\title{
ANALISIS KONTRIBUSI KOMPONEN TEKNOLOGI UMKM KOTA BONTANG MENGGUNAKAN METODE TEKNOMETRIK
}

\section{CONTRIBUTION ANALYSIS OF TECHNOLOGY COMPONENTS OF UMKM, BINTANG CITY}

\author{
1)Sella Antesty dan ${ }^{2)}$ Alva E. Tontowi \\ 1)Magister Teknik Sistem Fakultas Teknik UGM, Jalan Teknika Utara Yogyakarta. \\ 2)Departemen Teknik Mesin dan Industri Fakultas Teknik UGM, Jalan Grafika 2 Yogyakarta. \\ E-mail : sella.antesty@mail.ugm.ac.id
}

Diterima: 18-05-2020

Direvisi: 20-07-2020

Disetujui: 06-11-2020

\begin{abstract}
ABSTRAK
Keberadaan usaha mikro kecil menengah di suatu daerah seperti kota Bontang penting bagi daerah tersebut karena dapat meningkatkan kesejahteraan penduduknya lebih cepat dibanding dengan sektor lainnya. Industri tersebut perlu dibina sehingga tumbuh sehat agar produknya diminati pasar. Namun demikian, pembinaan tersebut tidak dapat efektif karena tidak ada peta teknometrik yang dapat digunakan sebagai acuan. Dalam studi ini, peta teknometrik industri dibuat dengan tujuan untuk mendapatkan peta kemampuan tingkat kontribusi teknologi yang dimiliki industri dan hasilnya didiskusikan. Usaha mikro kecil menengah berbasis pengolahan makanan yang tersebar di wilayah kota Bontang dijadikan sebagai obyek pemetaan dan metode teknometrik digunakan untuk menghitung tingkat kontribusi teknologi yang dimiliki. Hasil studi ini menunjukkan bahwa dari 4 aspek yang diteliti yang meliputi Technoware (fasilitas teknologi), Humanware (sumberdaya manusia), Infoware (kerangka kerja) dan Orgaware (manajemen) didapatkan hasil bahwa usaha mikro kecil menengah di kota Bontang masih menitik beratkan pada aspek humanware atau sumber daya manusia dengan kemampuan fasilitas teknologi produksi yang rendah.
\end{abstract}

Kata kunci: acuan, pembinaan, teknometrik, umkm

\begin{abstract}
The existence of Micro, Small, and Medium Enterprises in a region, such as Bontang City, is important for the area because it can improve the welfare of its population faster than in other sectors. The industry needs to be trained so that it grows healthy, thus its products are in demand by the market. However, the training cannot be effective because there is no technometric map that can be used as a reference. In this study, an industrial technometric map was made with the aim to obtain a map of the ability level of the technology contribution that the industry had and the results were discussed. Food processing-based Micro, Small, and Medium Enterprises which were distributed in Bontang City were used as mapping objects and the technometric method was used to calculate the level of technology contribution they had. Results of this study found that from the 4 aspects studied, including Technoware (technology facilities), Humanware (human resources), Infoware (framework) and Orgaware (management), it is found that Micro, Small, and Medium Enterprises in Bontang city still focused on the humanware aspect or human resources with low production technology facilities
\end{abstract}

Keywords: reference, technometric, training, SME

PENDAHULUAN

entang tahun 2017-2018, UMKM adalah unit yang paling banyak berkembang di Indonesia, bahkan mendominasi pangsa pasar sebesar 99,99\% dari keseluruhan industri di Indonesia. Sektor UMKM juga telah terbukti memberikan peranan penting dalam perekonomian Indonesia dengan memberikan kontribusi dalam 
proporsi PDB (Produk Domestik Bruto) Indonesia sebesar 61,07\% pada tahun 2018, dan serapan tenaga kerja dari sektor ini diketahui sebesar $97 \%$ pada tahun yang sama (Dinas Koperasi UMKM \& Perdagangan RI, 2019).

Melalui penurunan angka pengangguran terbuka, maka akan berdampak pada penguatan lain dibidang pengurangan jumlah kemiskinan, pemerataan pendapatan, pembangunan dalam bidang ekonomi, dan peningkatan kesejahteraan. Berdasarkan berbagai keunggulan yang dimiliki oleh sektor UMKM, maka penumbuhan dan pengembangan sektor tersebut dijadikan salah satu poin didalam RPJMN 2015-2019 (Rencana Pembangunan Jangka Menengah (RPJMN) Tahun 2015-2019, 2014).

Kota Bontang, terletak di Provinsi Kalimantan Timur dan memiliki luas wilayah sebesar 497,57 km², menjadikan Kota Bontang sebagai kota yang memiliki luasan wilayah terkecil di Provinsi Kalimantan Timur. Berdasarkan data komposisi Produk Domestik Regional Bruto (PDRB) Kota Bontang, diketahui bahwa proporsi sektor penyumbang PDRB terbesar adalah UMKM dari sektor industri pengolahan dimana sektor tersebut pada tahun 2018 memiliki kontribusi PDRB paling tinggi yaitu sebesar 82,2 \% (Badan Pusat Statistik Bontang, 2019). Artinya bahwa kinerja perekonomian Kota Bontang sangat bergantung pada kinerja sektor industri olahan, utamanya berbasis makanan dan minuman, industri tekstil, serta industri furnitur. Namun demikian, sektor UMKM di kota Bontang diketahui hanya memiliki tingkat pertumbuhan sebesar 0,2\% pada rentang waktu 2016-2018 (Dinas Koperasi UMKM \& Perdagangan Kota Bontang, 2018).

Rendahnya pertumbuhan dan perkembangan UMKM di Kota Bontang ditengarai akibat belum adanya peta tingkat kemampuan teknologi industri yang relevan dengan kebutuhan pasar di dalam maupun diluar kota Bontang. Adanya peta ini penting karena dapat digunakan untuk panduan pembinaan UMKM untuk bertumbuh dan berkembang dengan arah yang lebih jelas. Penelitian ini bertujuan sebagai pembuatan peta tingkat kemampuan teknologi UMKM berbasis pengolahan makanan di kota Bontang menggunakan metode teknometrik dari UNESCAP (United Nation Economics and Social Commission for Asia Pacific) dimana teknologi dipandang sebagai hasil interaksi dalam proses transformasi secara dinamis dari empat komponen dasar pembangunnya yaitu technoware (perwujudan didalam fasilitas/peralatan produksi), humanware (perwujudan didalam sumberdaya manusia sebagai pengguna/operator), Infoware (perwujudan didalam proses operasi/prosedur), Orgaware (perwujudan dalam manajerial) (Smith dan Sharif, 2007). Nilai Technology Contribution Coefficient (TCC/Koefisien Kontribusi Teknologi) merupakan hasil akhir dari metode teknometrik, yang kemudian diterjemahkan ke dalam skema penilaian untuk mengetahui klasifikasi tingkatan.

Berdasarkan berbagai penelitian yang telah dilakukan menggunakan model teknometrik sebagai metode pengukuran tingkat komponen teknologi, diketahui bahwa metode teknometrik dapat diterapkan pada berbagai tingkatan skala industri (industri kecil, industri menengah dan industri besar) baik barang maupun jasa, serta dapat digunakan untuk melihat daya saing industri.

(Warafakih et al., 2015) telah menggunakan metode ini untuk mengukur tingkatan kandungan teknologi pada layanan jasa telekomunikasi dan didapatkan hasil bahwa rentang teknologi yang dimiliki oleh objek penelitian berada pada klasifikasi baik dengan usulan penggunaan teknologi baru demi meningkatkan kecanggihan teknologi.

Sementara Yanthi et al. (2018) menganalisis kandungan komponen teknologi dengan kasus pada perusahaan jasa pengangkutan yaitu kereta api barang. Mereka menemukan bahwa status tingkatan teknologi pada unit usaha yang diteliti mencapai klasifikasi cukup. Diketahui pula bahwa nilai kontribusi yang terendah sebagai pembangun nilai komponen teknologi secara keseluruhan dimiliki oleh komponen technoware. Meskipun seharusnya, sebagai unit usaha pengoperasian angkutan barang, pemanfaatan teknologi mutlak 
diperlukan. Penerapan teknometrik pada industri jasa lainnya menemukan bahwa tingkatan teknologi yang dimiliki oleh objek penelitian berada pada klasifikasi semi modern dengan proporsi nilai penyumbang tingkat komponen teknologi terbesar berasal dari nilai komponen humanware (Giyanti, 2015).

Metode teknometrik dalam penerapannya juga dapat diintegrasikan dengan metode lainnya seperti AHP (Analytical Hierarchy Process) serta SMART (Simple Multi Atributte Rating Technique) dalam melakukan pembobotan dan pemberian peringkat/rating pada masingmasing komponen, kemudian SWOT (Strength Weaknees Opportunities Trade) untuk mendapatkan gambaran objek penelitian yang lebih komprehensif.

Adiantoro (2019) menggunakan kombinasi metode teknometrik dan ANP (Analytical Network Process), dalam mengukur kemampuan teknologi yang dimiliki oleh perusahaan yang bergerak dalam pembuatan kapal angkut. Hasil dari penelitian mengklasifikasikan objek penelitian berada pada rentang klasifikasi teknologi semi modern.

Penelitian dengan menggunakan metode teknometrik dengan fokus hanya pada salah satu komponen yaitu humanware dilakukan oleh (Lungari, 2017) pada industri galangan kapal kelas menengah. Lungari mendapatkan bahwa tingkatan klasifikasi teknologi yang dimiliki oleh objek penelitian berada pada level semi modern, sehingga arah usulan kebijakan yang diberikan berupa pemberian pelatihan dan sertifikasi bagi pekerja dalam rangka peningkatan sumber daya manusia.

Kombinasi atau integrasi metode teknometrik dengan metode lainnya seperti pada penelitian yang dilakukan oleh Sulistiyowati dan Jakaria (2018) menggunakan integrasi metode Teknometrik dan AHP (Analytical Hierarchy Process) di industri skala kecil yang bergerak pada bidang pembuatan ubin. Dalam penelitian tersebut ditemukan bahwa tingkat teknologi pada industri ubin tergolong rendah dan nilai komponen terendah dimiliki oleh komponen Orgaware. Berdasarkan hasil penelitian tersebut peneliti menyarankan perbaikan tingkat teknologi menggunakan metode Quality Function Development (QFD). Metode integrasi yang sama juga telah dilakukan oleh Wahyuni et al. (2016) pada unit UKM yang bergerak pada pengolahan kerupuk. Berdasarkan penelitian di UKM tersebut ditemukan bahwa tingkatan teknologi pada unit usaha yang diteliti termasuk dalam klasifikasi teknologi semi modern.

Sementara penelitian Pujianto et al. (2017) menggunakan integrasi metode teknometrik dengan SMART (Simple Multi Attribute Rating Technique) dan SWOT (Strength Weaknees Opportunities Trade) dilakukan pada industri pengolahan dengan skala besar yaitu perusahaan pengolahan biji kopi. Hasil dari penelitian tersebut ditemukan bahwa tingkat teknologi industri tersebut sudah mencapai tingkat modern. Penelitian lainnya yang mengintegrasikan metode teknometrik dengan lifecycle produk yang dilakukan oleh Smith dan Sharif (2007) bertujuan untuk melihat daya saing industri. Berdasarkan penelitian tersebut disimpulkan bahwa daya saing dapat ditingkatkan dan dikuatkan pada sumberdaya manusia, yang kemudian dilanjutkan pada penguatan atau pembaharuan teknologi.

Terkait life cycle, analisis inovasi yang didasarkan pada model teknometrik untuk memprediksi life cycle teknologi pada IKM sekaligus juga melakukan peramalan penjualan dilakukan oleh Rumanti dan Hadisurya (2017). Objek penelitian merupakan industri pengolahan barang kerajinan tangan. Berdasarkan didapatkan hasil bahwa pada objek penelitian yang diteliti memiliki tingkat teknologi yang rendah atau masih tradisional, namun memiliki nilai komponen humanware yang tinggi. Sedangkan berdasarkan hasil peramalan dapat diketahui pula jumlah item yang harus dijual demi tercapainya pengembangan usaha.

Jika penelitian yang telah didiskusikan dilakukan di Indonesia, penelitian menggunakan teknometrik juga telah dilakukan di Iran. Hasil dari penelitian ditemukan bahwa industri yang bergerak di bidang pengolahan berbahan plastik dan karet serta industri mesin dan peralatan telah mencapai level teknologi semi modern, sementara industri pengolahan produk mineral 
merupakan industri dengan nilai kontribusi komponen teknologi yang terendah atau teknologi tradisional (Rahmani et al., 2010).

Berdasarkan pada penelitian yang telah menggunakan metode teknometrik dan atau kombinasinya dengan metode lain yang telah dilakukan para peneliti di berbagai negara dan golongan industri baik barang maupun jasa, jelas nampak bahwa hasil penilaian tingkatan teknologi beragam dan bersifat lokalistik. Menurut (Purwaningsih et al., 2005) hasil dari nilai akhir Technology Contribution Coefficient (TCC/Koefisien Kontribusi Teknologi) sangat tergantung pada penentuan batas sotisfikasi, rentang batasan tingkat kecanggihan, dan nilai state of art. Namun demikian, hasil potret teknometrik di suatu industri masih dapat digunakan sebagai panduan awal untuk perbaikan industri itu sendiri dan pemangku kepentingan lainnya seperti pemerintah yang berkepentingan sebagai regulator dan fasilitator industri. Dalam konteks ini, penelitian dilakukan di Kota Bontang, Kalimantan Timur dengan tujuan untuk memetakan tingkat kandungan teknologi yang dimiliki oleh UMKM berbasis pengolahan makanan.

\section{METODOLOGI PENELITIAN}

Objek dalam penelitian ini adalah kandungan teknologi pada Usaha Mikro Kecil Menengah (UMKM) berbasis industri pengolahan makanan di kota Bontang, Kalimantan Timur dengan kerangka analisis penelitian seperti terlihat pada Gambar 1.

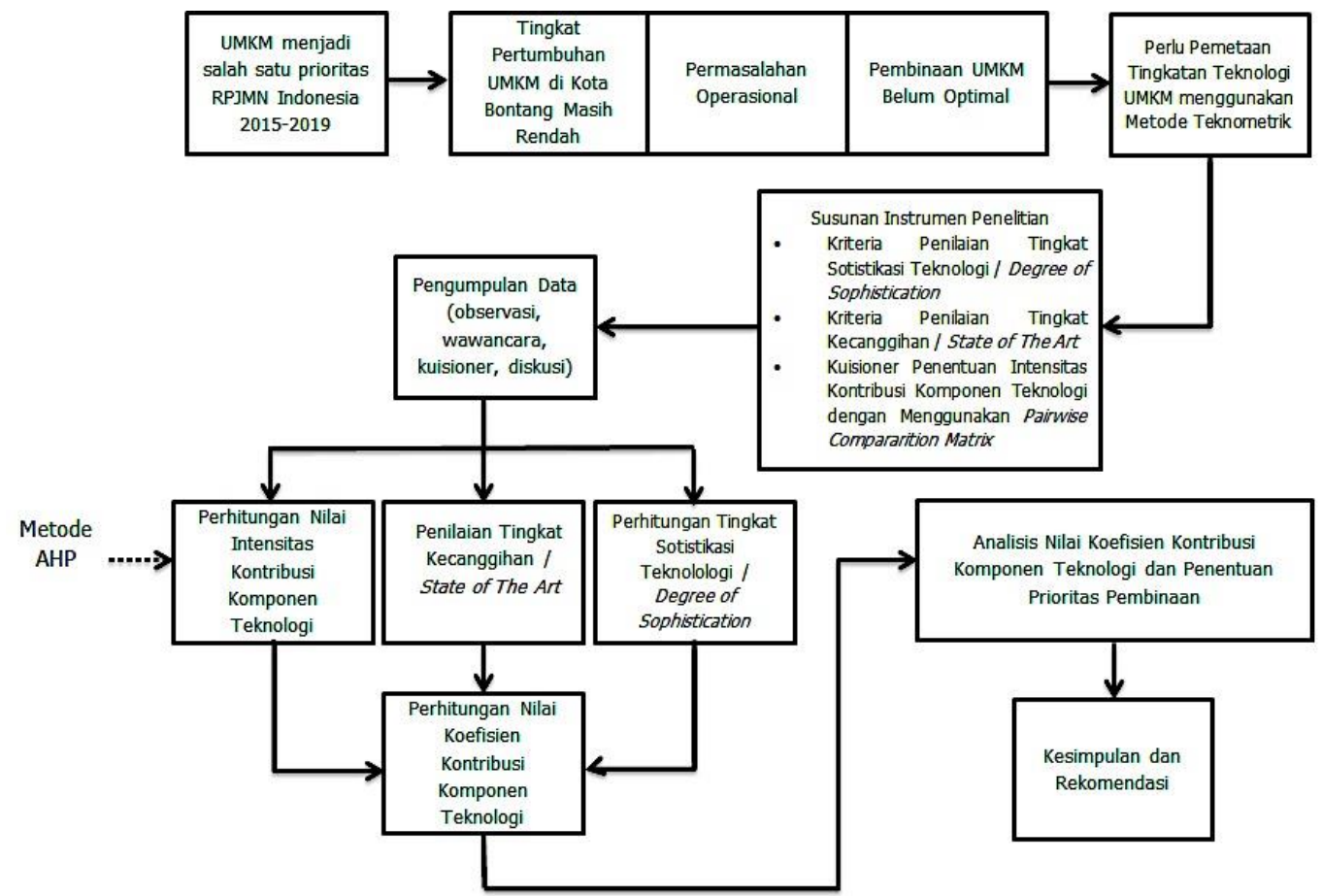

Gambar 1. Kerangka Analisis

\section{Data dan Responden Penelitian}

Dua data yang digunakan yaitu data primer dan data sekunder. Data primer berupa hasil pengumpulan dan pengolahan data melalui pengamatan dan wawancara langsung dengan responden atau pelaku UMKM pengolahan makanan (data batas atas: UT, UH, UI, UO; dan data batas bawah: LT, LH, LI dan LO). Pengamatan dan wawancara dilakukan menggunakan kuesioner yang dibuat berdasarkan kriteria generik UNESCAP. Sedangkan data sekunder berupa data omset pelaku usaha yang bernaung dibawah Asosiasi Pengusaha Makanan dan 
Minuman Kota Bontang. Penentuan jumlah responden kuisioner dilakukan menggunakan metode purposive sampling yang didasarkan pada 2 kriteria yaitu besar omset (tertinggi, sedang dan terendah) dan pelaku usaha harus bernaung dibawah asosiasi. Berdasarkan kedua kriteria tersebut diperoleh 4 UMKM makanan (OB, ZF, MA dan AJM) sebagai responden.

\section{Cara Pengambilan Data}

Data primer yang berupa data batas atas dan bawah ditetapkan ditentukan atau ditetapkan berdasarkan berdasarkan hasil observasi lapangan dan wawancara antara peneliti dengan responden pelaku UMKM dengan mengacu skor dalam Tabel-1 (Utomo \& Setiastuti, 2019).

Tabel 1. Derajat Kecanggihan

\begin{tabular}{|c|c|c|c|c|c|c|}
\hline \multicolumn{4}{|c|}{ Derajat Kecanggihan } & \multirow{2}{*}{\multicolumn{3}{|c|}{ Skor }} \\
\hline Technoware & Humanware & Inforware & Orgaware & & & \\
\hline $\begin{array}{l}\text { Peralatan } \\
\text { manual }\end{array}$ & $\begin{array}{l}\text { Kemampuan } \\
\text { pengoperasian } \\
\text { atau } \\
\text { penggunaan }\end{array}$ & $\begin{array}{l}\text { Fakta } \\
\text { pengenalan / } \\
\text { pembiasaan }\end{array}$ & $\begin{array}{l}\text { Kerangka } \\
\text { kerja usaha }\end{array}$ & 1 & 2 & 3 \\
\hline $\begin{array}{l}\text { Peralatan } \\
\text { bertenaga } \\
\text { penggerak }\end{array}$ & $\begin{array}{l}\text { Kemampuan } \\
\text { pengaturan, } \\
\text { pemasangan } \\
\text { atau persiapan }\end{array}$ & $\begin{array}{l}\text { Fakta } \\
\text { penguraian }\end{array}$ & $\begin{array}{l}\text { Kerangka } \\
\text { kerja ikatan }\end{array}$ & 2 & 3 & 4 \\
\hline $\begin{array}{l}\text { Peralatan } \\
\text { dengan } \\
\text { kemampuan } \\
\text { serbaguna } \\
\text { facilities) }\end{array}$ & $\begin{array}{l}\text { Kemampuan } \\
\text { memperbaiki }\end{array}$ & $\begin{array}{l}\text { Fakta } \\
\text { penggunaan } \\
\text { khusus }\end{array}$ & $\begin{array}{l}\text { Kerangka } \\
\text { kerja } \\
\text { penjelajahan }\end{array}$ & 3 & 4 & 5 \\
\hline $\begin{array}{l}\text { Peralatan } \\
\text { dengan tujuan } \\
\text { penggunaan } \\
\text { khusus }\end{array}$ & $\begin{array}{l}\text { Kemampuan } \\
\text { produksi }\end{array}$ & $\begin{array}{l}\text { Fakta } \\
\text { penggunaan }\end{array}$ & $\begin{array}{l}\text { Kerangka } \\
\text { kerja proteksi }\end{array}$ & 4 & 5 & 6 \\
\hline $\begin{array}{l}\text { Peralatan } \\
\text { otomatis }\end{array}$ & $\begin{array}{l}\text { Kemampuan } \\
\text { beradaptasi }\end{array}$ & $\begin{array}{l}\text { Fakta } \\
\text { pemahaman }\end{array}$ & $\begin{array}{l}\text { Kerangka } \\
\text { kerja } \\
\text { stabilitasi }\end{array}$ & 5 & 6 & 7 \\
\hline $\begin{array}{l}\text { Peralatan } \\
\text { terkom puterisasi }\end{array}$ & $\begin{array}{l}\text { Kemampuan } \\
\text { pengembangan }\end{array}$ & $\begin{array}{l}\text { Fakta } \\
\text { penyamarataan } \\
\text { secara umum }\end{array}$ & $\begin{array}{l}\text { Kerangka } \\
\text { kerja } \\
\text { perluasan } \\
\text { cakrawala }\end{array}$ & 6 & 7 & 8 \\
\hline $\begin{array}{l}\text { Peralatan } \\
\text { terpadu dan } \\
\text { terintegrasi }\end{array}$ & $\begin{array}{l}\text { Kemampuan } \\
\text { berinovas }\end{array}$ & Fakta penilaian & $\begin{array}{l}\text { Kerangka } \\
\text { kerja } \\
\text { unggulan }\end{array}$ & 7 & 8 & 9 \\
\hline
\end{tabular}

Data ini selanjutnya digunakan untuk menghitung Koefisien Kontribusi Teknologi menggunakan Persamaan (1).

\section{Cara Menghitung Koefisien kontribusi Teknologi}

Tingkat kecanggihan masing-masing UMKM secara kelembagaan diungkapkan dalam bentuk koefisien kontribusi teknologi (TCC; Technology Contribution Coefficient) yang merangkum aspek keseluruhan yaitu aspek teknologi $(T)$, sumber daya manusia $(H)$, informasi (I) dan organisasi (O), dan diformulasikan oleh UNESCAP (United Nation Economics and Social Commission for Asia Pacific) (Smith dan Sharif, 2007) seperti dalam Persamaan (1) dengan pengklasifikasian seperti deskripsi dalam Tabel-2. 


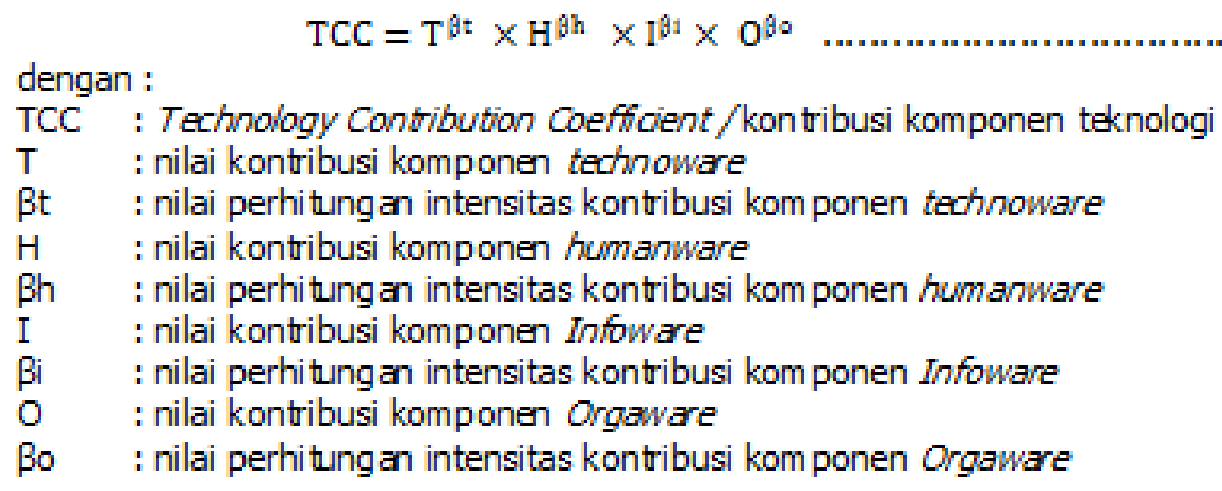

Tabel 2. Klasifikasi TCC

\begin{tabular}{cc}
\hline Nilai TCC & Klasifikas \\
\hline $0<\mathrm{T} C \mathrm{C}=0,1$ & Sangat rendah \\
$0,1<\mathrm{TCC}=0,3$ & Rendah \\
$0,3<\mathrm{TCC}=0,5$ & Cukup \\
$0,5<\mathrm{TCC}=0,7$ & Baik \\
$0,7<\mathrm{TCC}=0,9$ & Sangat Baik \\
$0,9<\mathrm{TCC}=1,0$ & Kecanggihan Muktahir \\
\hline
\end{tabular}

Nilai Kontribusi Komponen Teknologi masing-masing aspek ( $T, H$, I dan O) dihitung menggunakan Persamaan (2-5) (Matin \& Toloui, 2014):

$$
\begin{aligned}
& \mathrm{Ti}=\frac{1}{9}[\mathrm{LTi}+\mathrm{ST}(\mathrm{UT}-\mathrm{LT})] . \\
& \mathrm{Hj}=\frac{1}{9}[\mathrm{LHj}+\mathrm{SH}(\mathrm{UH}-\mathrm{LH})] \\
& \mathrm{I}=\frac{1}{9}[\mathrm{Li}+\mathrm{SI}(\mathrm{UI}-\mathrm{LI})] \ldots \ldots . . . \\
& \mathrm{O}=\frac{1}{9}[\mathrm{LO}+\mathrm{SO}(\mathrm{UO}-\mathrm{LO})] . .
\end{aligned}
$$

dengan:

LT : lower limit komponen technoware

UT : upper limit komponen technoware

ST : State of the art komponen technoware

$\mathrm{LH}$ : lower limit komponen humanware

$\mathrm{SH}$ : State of the art komponen humanware

$\mathrm{UH}$ : upper limit komponen humanware

LI : lower limit komponen Infoware

UI : upper limit komponen Infoware

SI : State of the art komponen Infoware

LO : lower limit komponen Orgaware

SO : State of the art komponen Orgaware

$\mathrm{UH}$ : upper limit komponen humanware

Sedangkan batas atas (UT, UH, UI dan UO) dan batas bawah (LT, LH, LI dan LO) ditentukan menggunakan Tabel-1 berdasarkan hasil pengamatan dan wawancara ke pelaku UMKM. Tingkat kecanggihan $\left(\mathrm{ST}_{\mathrm{i}}, \mathrm{SH}_{\mathrm{j}}\right.$, SI dan SO) dihitung menggunakan Persamaan (6-9) (Ayu, 2018):

- Technoware

$$
\begin{aligned}
& \mathrm{ST}_{\mathrm{i}}=\frac{1}{10}\left[\frac{\sum_{\mathrm{k}=1}^{\mathrm{k}_{\mathrm{t}}} \mathrm{t}_{\mathrm{ik}}}{\mathrm{k}_{\mathrm{t}}}\right] \\
& \text { dengan: }
\end{aligned}
$$


$\mathrm{k}_{\mathrm{t}}=$ jumlah kriteria komponen technoware

$\mathrm{t}_{\mathrm{ik}}=$ nilai kriteria ke-k dari technoware kategori $\mathrm{i}$

- Humanware

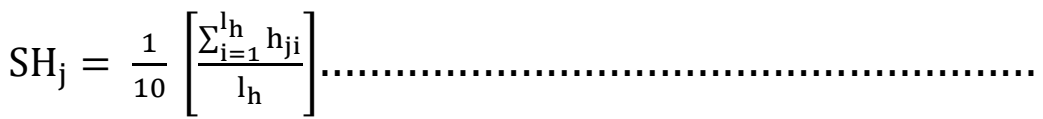

dengan:

$I_{\mathrm{h}}=$ jumlah kriteria komponen humanware

$\mathrm{h}_{\mathrm{ij}}=$ nilai kriteria ke-i dari humanware kategori $\mathrm{j}$

- Infoware

$$
\mathrm{SI}=\frac{1}{10}\left[\frac{\sum_{\mathrm{m}=1}^{\mathrm{m}_{\mathrm{f}}} \mathrm{f}_{\mathrm{mi}}}{\mathrm{m}_{\mathrm{f}}}\right]
$$

dengan:

$\mathrm{m}_{\mathrm{f}}=$ jumlah kriteria komponen Infoware

$\mathrm{f}_{\mathrm{mi}}=$ nilai kriteria ke-m dari Infoware pada tingkat usaha

- Orgaware

$$
\mathrm{SO}=\frac{1}{10}\left[\frac{\sum_{\mathrm{n}=1}^{\mathrm{n}_{\mathrm{o}} \mathrm{O}_{\mathrm{n}}}}{\mathrm{n}_{\mathrm{o}}}\right]
$$

dengan:

$\mathrm{n}_{\mathrm{o}}=$ jumlah kriteria komponen Orgaware

$\mathrm{O}_{\mathrm{n}}=$ nilai kriteria ke-n dari Infoware pada tingkat usaha

Nilai hasil perhitungan Intensitas Kontribusi Komponen Teknologi yaitu $\beta \mathrm{t}, \beta \mathrm{h}, \beta \mathrm{i}$ dan $\beta \mathrm{o}$ didapatkan menggunakan metode Analytic Hierarchy Process (AHP) dengan penggunaan matriks perbandingan berpasangan (pairwise comparison matrix) diantara masing-masing komponen T, H, I, O. Syarat konsistensi dalam pengisian kuesioner ini mutlak diperlukan yang diungkapkan dalam bentuk nilai rasio konsistensi. Nilai rasio konsistensi harus bernilai $\leq 0,1$ dan nilai nilai $\beta \mathrm{t}, \beta \mathrm{h}, \beta \mathrm{i}$, $\beta$ o merupakan nilai normalized weight.

\section{HASIL DAN PEMBAHASAN}

Hasil pemetaan teknometrik UMKM-makanan kota Bontang dijelaskan dalam bentuk grafik radar yang meliputi 4 aspek (technoware, humanware, Infoware dan Orgaware). Rincian dari keseluruhan hasil adalah (1) analisis tingkat kecanggihan, (2) analisis state of the art, (3) analisis kontribusi komponen teknologi (4) analisis intensitas komponen teknologi dan (5) analisis koefisien kontribusi teknologi.

\section{Analisis Tingkat Kecanggihan}

Berdasarkan penelitian yang telah dilakukan diketahui bahwa rentang batas UMKM berbasis pengolahan makanan untuk komponen technoware berada pada rentang nilai 1 sampai dengan 3. Fasilitas produksi yang dimiliki masih menggunakan peralatan dan tenaga manual serta penggunaan peralatan bersumberdaya penggerak dalam produksi terbatas pada blender dan sealer. Sedangkan komponen humanware atau sumberdaya manusia, memiliki rentang batas bawah 1 dan batas atas 5 . Umumnya para pelaku UMKM berbasis pengolahan makanan telah memiliki kemampuan untuk melakukan operasi, kemampuan melakukan persiapan bahan baku, kemampuan melakukan perbaikan, kemampuan melakukan produksi dan kemampuan melakukan adaptasi terhadap produk lain. Pada komponen infoware, diketahui memiliki rentang batas bawah 1 dan batas atas 4. Pemberian informasi kepada pihak luar antara lain fakta pengenalan dan penjelasan mengenai perolehan bahan baku, aspek permodalan, proses produksi, produk jadi dan pasar. Pengelolaan manajerial yang diwakili oleh komponen orgaware, memiliki rentang batas 
bawah 1 dan batas atas 3. Manajemen usaha yang dimiliki umumnya masih berada dalam tahap usaha kecil, permodalan pribadi, kepemilikan tunggal, pemilik merangkap sebagai pekerja dan jam kerja yang tidak tetap.

\section{Analisis Nilai State of The Art}

Hasil perhitungan nilai tingkat kecanggihan (state of the art) komponen technoware pada UMKM berbasis pengolahan makanan berada kisaran 0,2 - 0,3367. Keseluruhan proses produksi umumnya masih dilakukan secara manual. Telah ada pengujian kualitas bahan baku secara sederhana contohnya seperti melalui pengujian visual dan penciuman, beserta dengan standar baku pembuatan seperti komposisi campuran dan lama proses pengolahan, tetapi belum memiliki alat pengontrol untuk mengetahui kualitas bahan baku standar dan produk olahan jadi. Contoh seperti kandungan minyak pada produk abon, atau jumlah kandungan air pada produk terasi kering. Padahal, hal tersebut seharusnya menjadi perhatian, mengingat produk makanan merupakan salah satu produk yang rentan tercemar dan berimbas langsung pada manusia sebagai konsumen. Sedangkan nilai tingkat kecanggihan (state of the art) komponen humanware pada UMKM berbasis pengolahan makanan berada kisaran 0,42308 0,65385 . Keterampilan pemilik dalam membuat produk termasuk berada dalam kategori tinggi. Hal ini tidak mengherankan, mengingat pemilik juga adalah merupakan pekerja dalam unit usaha. Secara umum, belum ada rencana untuk mengembangkan bisnis dalam bentuk produk lain. Pemilik belum berani untuk melakukan inovasi produk, mengingat aspek pemodalan yang juga terbatas dan segment pasar yang masih belum jelas. Produk hasil sudah melewati pengujian sederhana sebelum dilakukan pengemasan. Umumnya pengemasan sudah dalam bentuk design yang menarik, menggunakan alat vacuum dan sealer walaupun ada juga yan menggunakan kemasan botol plastik. Apabila pesanan diterima dalam jumlah banyak, umumnya pemilik melakukan perekrutan tenaga kerja lepas yang berasal dari lingkungan sekitar ataupun kerabat yang sudah dikenal. Seluruh pemilik adalah ibu rumah tangga, sehingga proses produksi dan jam kerja terkadang disesuaikan dengan keperluan keluarga. Proses produksi tidak dilakukan setiap hari, tetapi bergantung pada stok produk hasil produksi sebelumnya yang sudah habis karena laku terjual. Kegiatan promosi dan pemasaran dilakukan didepan rumah dengan cara menaruh produk-produk sebagai display dan pemberian spanduk produk sebagai sarana periklanan.

Pada perhitungan nilai tingkat kecanggihan (state of the art) komponen Infoware UMKM berbasis pengolahan makanan berada pada kisaran 0,34167-0,46667. Secara umum pemilik melakukan pembukuan catatan terutama yang berkaitan dengan keuangan. Pemilik juga aktif berkomunikasi dengan sesama pelaku usaha yang bergabung dibawah asosiasi dengan cara memanfaatkan teknologi internet yaitu whatsapp. Cara dalam melakukan kegiatan pemasaran antara lain, pemilik juga telah memanfaatkan kemajuan teknologi yaitu internet dengan cara memiliki akun sosial media yang bertujuan untuk melakukan kegiatan promosi produk. Nilai tingkat kecanggihan (state of the art) komponen Orgaware pada UMKM berbasis pengolahan makanan diketahui berada kisaran 0,35714-0,71429. Kegiatan organisasi didalam unit usaha umumnya hanya berlaku pada hubungan dengan stakeholder terkait seperti supplier dan distributor, hal ini dikarenakan status kepemilikan unit usaha adalah status kepemilikan tunggal sehingga pemilik juga merangkap sebagai pekerja. Tidak ada jam atau jadwal kerja khusus yang diberlakukan setiap harinya, disesuaikan dengan kelonggaran waktu dari pemilik yang merupakan Ibu Rumah Tangga dan ketersediaan stok produksi sebelumnya.

\section{Analisis Kontribusi Komponen Teknologi}


Berikut adalah Tabel 3 yang berisi nilai kontribusi komponen teknologi industri UMKM berbasis pengolahan makanan beserta grafik kontribusi technoware humanware Infoware Orgaware (THIO) pada Gambar 4.

Tabel 3. Nilai THIO UMKM Berbasis Pengolahan Makanan

\begin{tabular}{|c|l|c|c|c|c|}
\hline \multirow{2}{*}{ No } & \multirow{2}{*}{$\begin{array}{c}\text { Nama } \\
\text { UMKM }\end{array}$} & \multicolumn{4}{|c|}{ Nilai THIO } \\
\cline { 3 - 6 } & & \multicolumn{4}{|c|}{ UMKM Makanan } \\
\cline { 3 - 6 } & & $\mathbf{T}$ & $\mathbf{H}$ & $\mathbf{I}$ & $\mathbf{0}$ \\
\hline 1 & OB & 0,29704 & 0,64957 & 0,1537 & 0,16667 \\
\hline 2 & ZF & 0,28222 & 0,15812 & 0,15833 & 0,31746 \\
\hline 3 & MA & 0,29704 & 0,71795 & 0,16296 & 0,19048 \\
\hline 4 & AJM & 0,29704 & 0,73504 & 0,44722 & 0,15079 \\
\hline
\end{tabular}

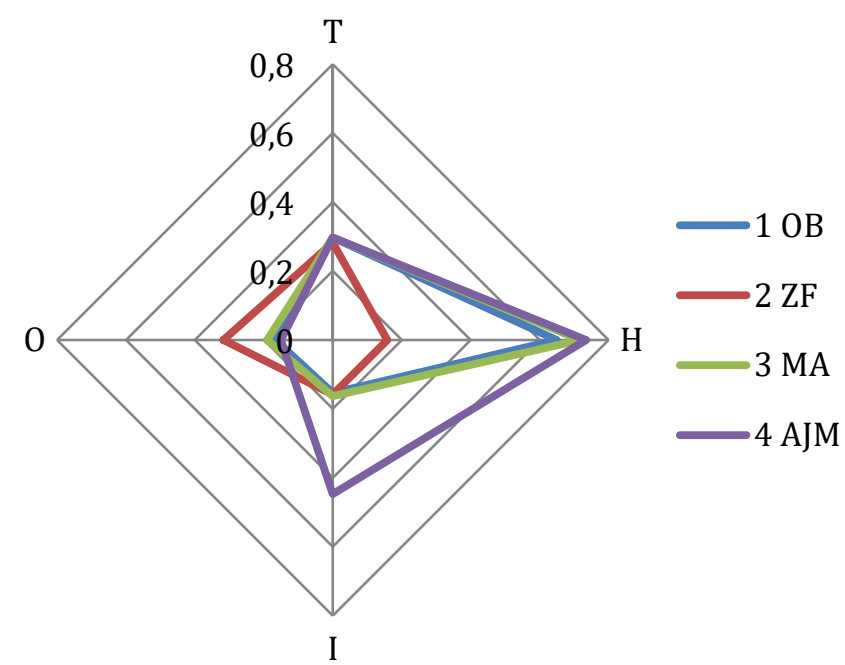

Gambar 2. Grafik technoware humanware Infoware Orgaware (THIO) UMKM Pengolahan Makanan

\section{Analisis Intensitas Komponen Teknologi}

Adapun dalam mendapatkan nilai analisis intensitas komponen teknologi didapatkan dari penggunaan metode Analytic Hierarchy Process (AHP) serta software expert choice sebagai pengolahan data. Berdasarkan rumus TCC pada Persamaan 9, intensitas komponen dengan nilai tertinggi akan memiliki pengaruh dan potensi besar dalam menaikkan nilai technology contribution coefficient (TCC). Hasil penilaian intensitas kontribusi komponen teknologi disajikan pada Tabel 4.

Tabel 4. Intensitas Kontribusi Komponen Teknologi

\begin{tabular}{|c|l|c|c|c|c|}
\hline \multirow{2}{*}{ No } & \multirow{2}{*}{ Nama Usaha } & \multicolumn{4}{|c|}{$\begin{array}{c}\text { Nilai Intensitas Kontribusi } \\
\text { Teknologi }\end{array}$} \\
\cline { 3 - 6 } & & $\boldsymbol{\beta t}$ & $\boldsymbol{\beta h}$ & $\boldsymbol{\beta i}$ & $\boldsymbol{\beta 0}$ \\
\hline 1 & OB & 0,22 & 0,579 & 0,092 & 0,11 \\
\hline 2 & ZF & 0,389 & 0,178 & 0,303 & 0,13 \\
\hline 3 & MA & 0,208 & 0,613 & 0,089 & 0,089 \\
\hline 4 & AJM & 0,208 & 0,613 & 0,089 & 0,089 \\
\hline
\end{tabular}

\section{Analisis Technology Contribution Coefficient (TCC)}


Berdasarkan analisa data yang telah dilakukan dan didasarkan pada klasifikasi nilai TCC pada Tabel 2, maka dapat disimpulkan bahwa untuk unit usaha OB, MA dan AJM berada pada klasifikasi teknologi cukup. Sedangkan unit usaha ZF masih berada pada klasifikasi teknologi rendah. Pada unit usaha dengan klasifikasi teknologi cukup (OB, MA, dan AJM), komponen sumber daya manusia merupakan penyumbang nilai komponen terbesar yang memberi kontribusi nilai TCC. Sedangkan pada unit usaha dengan klasifikasi teknologi rendah (ZF), komponen penyumbang terbesar nilai TCC adalah dari kemampuan manajemen organisasi. Berikut adalah Tabel 5 yang berisi nilai Kontribusi Komponen dari Teknologi/ Technology Contribution Coefficient (TCC).

Tabel 5. Nilai Technology Contribution Coefficient (TCC)

\begin{tabular}{|c|c|c|c|c|}
\cline { 2 - 5 } \multicolumn{1}{c|}{} & OB & ZF & MA & AJM \\
\hline $\begin{array}{c}\text { Nilai } \\
\text { TCC }\end{array}$ & 0,412200116 & 0,216964917 & 0,465491344 & 0,506019083 \\
\hline
\end{tabular}

\section{KESIMPULAN}

UMKM berbasis pengolahan makanan di kota Bontang memiliki rentang teknologi rendah ( $\mathrm{TCC}=0,21690)$ sampai dengan cukup $(\mathrm{TCC}=0,5060)$ dengan nilai komponen humanware sebagai penyumbang terbesar dalam proporsi keseluruhan nilai TCC. Hal ini mengindikasikan bahwa, UMKM berbasis pengolahan makanan di Kota Bontang dalam menjalankan usahanya masih menitik beratkan pada kemampuan sumber daya manusia (SDM) dalam melakukan produksi, inovasi dan kreatifitas dalam pengembangan produknya dengan nilai komponen humanware $(\mathrm{H})=0,7350$. Kemudian, priorotas dibawah SDM berturut-turut adalah komponen Infoware $(\mathrm{I})=0,4472$, Orgaware $(\mathrm{O})=0,3174$ dan technoware $(\mathrm{T})=0,2970$. Nilai technoware yang rendah mengindikasikan bahwa usaha mikro kecil menengah (UMKM) berbasis pengolahan makanan belum melakukan adaptasi teknologi pada fasilitas produksi.

\section{SARAN}

Usulan prioritas yang diberikan sebagai pembinaan dengan urutannya dimulai dari teknologi fasilitas produksi, kompetensi sumberdaya manusia, sistem informasi dan manajemen organisasi dengan pemetaan yang sebaiknya dilakukan secara regular per 5 tahunan atau kurang dari 5 tahun disesuaikan dengan perkembangan kebutuhan penyesuaian pasar.

\section{UCAPAN TERIMA KASIH}

Penelitian ini terwujud atas Kerjasama antara Pusat Studi Energi UGM dengan Pemerintah Daerah Kota Bontang Kalimantan Timur Tahun 2019 dalam rangka penyusunan Rencana Pembangunan Industri Kota Bontang (RPIK). Untuk itu penulis mengucapkan terima kasih.

\section{DAFTAR PUSTAKA}

Adiantoro, B. 2019. Analisis Kemampuan Teknologi PT X dengan Pendekatan Teknometrik dan Analytical Network Process ( ANP ). Jurnal Maritim Indonesia 7: 176-185.

Badan Pusat Statistik Bontang. 2019. Kota Bontang Dalam Angka. Bontang.

Dinas Koperasi UMKM \& Perdagangan Kota Bontang. 2018. Laporan Akuntabilitas Kinerja Dinas Koperasi, UKM \& Perdagangan Kota Bontang. Bontang.

Dinas Koperasi UMKM \& Perdagangan RI. 2018. Perkembangan Data Usaha Mikro , Kecil , Menengah Dan Usaha Besar. Jakarta.

Giyanti, I. 2015. Penilaian Tingkat Kontribusi Teknologi pada Perusahaan Jasa Menggunakan Model Teknometrik. Jurnal IImiah Teknik Industri Dan Informasi 3(2): 93-106.

Lungari, F. F. 2017. Analisis Kesiapan Komponen Teknologi ( Humanware) di Galangan Kapal Menengah ( Studi Kasus PT Adiluhung Sarana Segara Indonesia ). Jurnal IImiah Tindalung 
3(1): 31-35.

Matin, Y. A., \& Toloui, A. 2014. Measuring Technological Level and Capability of the Industries in East Azerbaijan and Providing Proper Strategies for Improvement and Promotion of Technology. Advances in Environmental Biology 8(25): 408-413.

Peraturan Presiden RI. Rencana Pembangunan Jangka Menengah (RPJMN) tahun 2015-2019 1311.2014.

Pujianto, T., Hasbullah, R. A. S., \& Ardiansah, I. 2017. Penilaian Kontribusi Komponen Teknologi dalam Aktivitas Produksi di PT Z Menggunakan Metode Teknometrik. Jurnal Teknologi Dan Manajemen Agroindustri 6(3): 133-144.

Purwaningsih, R., Prastawa, H., \& R, F. Z. 2005. Penilaian Teknologi Dengan Metode Teknometrik Di PT. Indo Acidatama Chemical Industri Solo. Jurnal Transistor 5(1): 1220.

Rahmani, K., Behravesh, M., Behravesh, M., Karegar, N., \& Fereidooni, A. 2010. Examining The Level and Strength of Technology In The Industries of The Country Iran by Using Escap Model and Introducing Solutions for Developing Technology. Australian Journal of Basic and Applied Sciences 4(10): 4638-4649.

Ayu, R.A., 2018. Analisis Kontribusi Komponen Teknologi Dalam Pengembangan Pertanian Padi Konvensional Menuju Organik dan Pengaruhnya Terhadap Produksi Padi Dan Produksi, Produktivitas dan Pendapatan Usaha Tani di Kecamatan Sambirejo, Kabupaten Sragen. Universitas Pembangunan Nasional. Yogyakarta.

Retnowati, N., Mayasari, F. 2016. Contribution Assesment of Technology Component at PDP KAHYANGAN Kabupaten Jember. Jurnal IImiah Inovasi 1(3): 193-199.

Rumanti, A. A., \& Hadisurya, V. 2017. Analysis of Innovation based on Technometric Model to Predict Technology Life Cycle in Indonesian SME. International Journal of Innovation in Enterprise System 1(01): 29-36.

Smith, R., \& Sharif, N. 2007. Understanding and Acquiring Technology Assets for Global Competition. Technovation 27(11): 643-649.

Sulistiyowati, W., \& Jakaria, R. B. 2018. Assessment of Technology Content Level With Integrated Technometrics and Analytical Hierarchy Process (AHP) Methods in small and medium enterprises. IOP Conference Series: Materials Science and Engineering. Annual Applied Science And Engineering Conference 434(1) :1-10.

Utomo, S., \& Setiastuti, N. 2019. Penerapan Metode Technometrik Untuk Penilaian Kapabilitas Teknologi Industri Galangan Kapal Dalam Menyongsong Era Industri 4.0. J-SAKTI (Jurnal Sains Komputer Dan Informatika) 3(1): 100.

Wahyuni, H. C., Hartati, V., \& Astuti, M. 2016. Model Adopsi Teknologi Dalam Rangka Peningkatan Kualitas Produk Pada Usaha Kecil Dan Menengah (UKM) Di Kabupaten Sidoarjo. Spektrum Industri 14(2): 189.

Warafakih, A. S., Chumaidiyah, E., Aurachman. 2015. Analisis Kandungan Teknologi 3G Pada Layanan Telkomsel Flash Dengan Metode Teknometrik Di PT . TELKOMSEL JAKARTA SELATAN. Proceeding of Engineering 2(2): 4124-4131.

Yanthi, E. R., Basith, A., \& Munandar, J. M. 2018. Analisis Kontribusi Komponen Teknologi pada Perusahaan Jasa Kereta Api Barang dengan Pendekatan Model Teknometrik. Jurnal Manajemen Teknologi 17(3): 197-215. 